\title{
PERBANDINGAN HASIL UJI SCHIRMER TEST I SEBELUM DAN SESUDAH 2 JAM MENGGUNAKAN KOMPUTER PADA MAHASISWA DI UNIVERSITAS KOMPUTER INDONESIA
}

\author{
Arief Witjaksono ${ }^{1)}$, Anisa Carolina ${ }^{2)}$ \\ ${ }^{1,2)}$ Program Studi Diploma Tiga Refraksi Optisi STIKes Dharma Husada \\ 1) awicaks07@yahoo.co.id \\ 2) anisacarolina6@gmail.com
}

\begin{abstract}
ABSTRAK
Penurunan jumlah refleks berkedip berperan terhadap rendahnya produksi air mata dan secara temporer menimbulkan stres pada kornea dan mengakibatkan mata kering. Untuk mengurangi kemugkinan terjadinya mata kering ketika menggunakan komputer, dianjurkan untuk lebih sering berkedip untuk menjaga kelembaban permukaan okular. Refleks berkedip yang tidak sempurna juga ditemukan pada pengguna komputer yang juga berdampak terhadap stabilitas air mata. Tujuan penelitian ini untuk mengetahui perbedaan hasil uji schirmer test I sebelum dan sesudah 2 jam penggunaan komputer. Jenis Penelitian dengan Pre dan Post sebelum dan sesudah 2 jam menggunakan komputer secara cross sectional dengan metode penelitian menggunakan purposive sampling dengan metode perhitungan Uji Wilcoxon. Penelitian ini menggunakan Tes Schirmer dan Lembar Observasional. Hasil penelitian di dapat bahwa 23 orang (76.7\%) sesudah 2 jam menggunakan komputer dikategorikan mengalami Non Dry Eye, kemudian sebanyak 3 orang (10.0\%) dikategorikan mengalami Dry Eye Ringan dan 7 orang (13.3\%) dikategorikan Dry Eye Sedang dari jumlah sampel sebanyak 30 orang. Terdapat perbedaan sebelum dan sesudah menggunakan komputer $(p=0.03)$. Disarankan agar tidak menggunakan komputer pada jam istirahat mengistirahatkan mata, mengatur tingkat kesilauan komputer, dan mengatur jarak pandang ke layar.
\end{abstract}

Kata kunci : Uji Schirmer Test Sebelum dan Sesudah, Perbandingan, Penggunaan Komputer

\section{ABSTRACT}

A decrease in the number of flashing reflexes plays a role in the low production of tears and temporarily stresses the cornea and results in dry eyes. To reduce the possibility of dry eyes when using a computer, it is recommended to blink more often to maintain ocular surface moisture. Imperfect flashing reflexes are also found in computer users which also have an impact on tear stability. The purpose of this study was to determine the differences in the results of the Schirmer test I test before and after 2 hours of computer use. This type of research with Pre and Post before and after 2 hours using a computer cross-sectional method with the research method using purposive sampling with the Wilcoxon Test calculation method. This study used the Schirmer Test and Observational Sheet. The results showed that 23 people (76.7\%) after 2 hours using computers were categorized as experiencing Non Dry Eye, then as many as 3 people (10.0\%) were categorized as having mild dry eye and 7 people (13.3\%) categorized as moderate dry eye from the number of samples 30 people. There are differences before and after using a computer $(p=0.03)$. It is recommended that you do not use the computer at rest time to rest your eyes, adjust the brightness of the computer, and adjust the visibility to the screen.

Keyword : Schirmer Test Test Before and After, Comparison, Computer Use 


\section{PENDAHULUAN}

Abad ke-21 komputer digunakan hampir pada semua kegiatan, manusia seolah-olah sudah sangat tergantung pada kemampuan komputer yang diciptakan untuk membantu aktivitas (Anies, dalam Suci Febrianti, 2018).

Data organisasi kesehatan dunia (WHO) menunjukkan angka kejadian Computer Vision Syndrome (CVS) tahun 2004 berkisar 40-90\% diantara pengguna komputer dan sudah diperkirakan hampir 60 juta orang menderita CVS secara global dan sekitar satu juta kasus baru terjadi setiap tahunnya (Akinbinu \& Mashalla dalam Suci Febrianti, 2018). Pada saat menggunakan komputer biasanya seseorang akan terfokus pada layar komputer dalam waktu yang cukup lama, hal tersebut dapat menyebabkan masalah pada mata seperti mata kering, kemerahan, iritasi, mata lelah, mata tegang, pandangan kabur sementara, peka terhadap rangsang cahaya dan masalah otot sebagai akibat penggunaan komputer (Wimalasundera, Ansel, dalam Muchamad Sugarindra, 2017).

Penggunaan komputer dalam waktu yang lama dan jarak yang kurang dari standar ukur dapat menimbulkan kelelahan mata seperti pegal, mata pedih, mata berair, mata merah dan penglihatan kabur Jurnal Penelitian Kesehatan STIKes Dharma Husada Bandung
(Affandi dalam Taufan Elfananda, 2007). Mata pedih dalam penggunaan komputer juga dapat disebabkan oleh kurangnya refleks berkedip pada saat memusatkan penglihatan pada layar komputer. Studi menunjukkan bahwa tingkat mengedipkan mata para pekerja yang berhadapan dengan komputer masih sangat rendah. Pada pengguna VDT (Video Display Terminal) seperti komputer, reflex berkedipnya berkurang 66\% yaitu 3-6 kali per menit. Ini menyebabkan mata menjadi kering. Selain itu juga menyebabkan ketegangan pada otot mata (Melati Aisyah Permana, Koesyanto dkk,2015).

Penurunan jumlah refleks berkedip berperan terhadap rendahnya produksi air mata dan secara temporer menimbulkan stres pada kornea dan mengakibatkan mata kering. Untuk mengurangi kemugkinan terjadinya mata kering ketika menggunakan komputer, dianjurkan untuk lebih sering berkedip untuk menjaga kelembaban permukaan okular. Refleks berkedip yang tidak sempurna juga ditemukan pada pengguna komputer yang juga berdampak terhadap stabilitas air mata (Muhammad Irfan Dwiputra Rianil, Wildan dkk,2018).

Seseorang yang menggunakan komputer dalam waktu yang cukup lama juga dihadapkan pada penurunan frekuensi 
mengedip. lapisan air mata yang normal dibersihkan dan diganti melalui proses mengedip oleh kelopak mata. Reflek mengedip adalah salah satu reflek tercepat yang sudah ada ketika lahir. Jumlah kedipan bervariasi dengan aktifitas yang berbeda, cepat ketika kita sedang aktif, dan lambat ketika kita sedang sedatif atau berkonsentrasi. Penelitian menunjukan bahwa frekuensi mengedip pada pengguna komputer menurun drastis selama melakukan aktifitas dengan menggunakan komputer. Hal ini disebabkam konsentrasi terhadap aktifitas dan pergerakan mata yang terbatas sehingga terjadi penurunan produksi air mata atau peningkatan penguapan air mata (Imgardis Teti, 2012).

Namun sebaliknya, pada beberapa pengguna komputer dilaporkan mengeluh mata berair. Penjelasan yang memungkinkan mengenai mata berair selama penggunaan komputer dihubungkan dengan kompensasi terhadap mata kering yang akan memicu refleks lakrimasi. Menurut Haine refleks air mata memiliki komposisi yang berbeda dengan air mata normal yang dibutuhkan untuk membasahi permukaan mata. Refleks lakrimasi terdiri dari aquos dalam jumlah banyak namun komposisi musin dan lipidnya sangat sedikit (Muhammad Irfan Dwiputra Rianil, Wildan dkk,2018). 
- Mintalah pasien untuk melihat ke atas dan degan jari telunjuk, tarik perlahan kelopak mata bagian bawah

- Kaitkan ujung lengkung strip di atas kelopak mata bagian bawah dan biarkan benda itu 'duduk' di dalam

- Perhatikan waktunya

- Minta pasien untuk tidak memejamkan mata dengan kuat, tapi hanya untuk menjaga agar mata tetap tertutup rapat

- Setelah 5 menit, mintalah pasien untuk membuka kedua mata dan melihat ke atas.

- Hati-hati lepaskan strip

- Dengan menggunakan skala paket, ukur panjang area yang dilembabkan di strip dan tandai dengan tanda pulpen

- Tempelkan strip ke dokumentasi pasien dan catat pengukuran di bawah masing-masing strip, misalnya,"10 $\mathrm{mm}$ dalam 5 menit". Jika strip benar-benar dibasahi sebelum 5 menit, rekam dengan tepat, misalnya, “30 mm dalam 3 menit".

Definisi Operasional yang digunakan dalam penelitian :

- Non Dry Eye, jika ukuran kertas yang basah > $15 \mathrm{~mm}$ dalam waktu 5 menit.

- Dry eye Ringan, jika ukuran kertas yang basah 9 - 14 mm dalam waktu 5 menit.

- Dry eye Sedang, jika ukuran kertas yang basah 4 - 8 mm dalam waktu 5 menit.

Data hasil uji Schirmer dikumpulkan untuk dianalisa menggunakan teknik analisa univariat dan Wilcoxon Signed Rank Test. Analisa univariant dilakukan masing-masing variabel atau mendeskripsikan karakteristik setiap variabel penelitian. Wolcoxon signed rank test digunakan apabila data tidak berdistribusi normal.

\section{HASIL DAN PEMBAHASAN}

a. Hasil

\section{Tabel 1 Karakteristik berdasarkan Jenis} kelamin.

\begin{tabular}{ccc}
\hline Jenis Kelamin & F & Persentase $(\%)$ \\
\hline Perempuan & 5 & 16,7 \\
\hline Laki-Laki & 25 & 83,3 \\
\hline Total & 30 & 100 \\
\hline
\end{tabular}

Karakteristik subjek pada penelitian ini yang diambil adalah Perempuan $16.7 \%$ dan Laki-Laki $83.3 \%$ dengan jumlah responden 30 orang.

Tabel 2 Karakteristik Berdasarkan Usia

\begin{tabular}{ccc}
\hline Usia & F & Persentase $(\%)$ \\
\hline 20 & 9 & 30,0 \\
\hline 21 & 19 & 63,3 \\
\hline 22 & 2 & 6,7 \\
\hline Total & 30 & 100 \\
\hline
\end{tabular}

Karakteristik subjek pada adalah dewasa muda yang berusia 20 tahun $30.0 \%, 21$ tahun $63.3 \%, 22$ tahun $6.7 \%$.

\section{Tabel 3 Distribusi Frekuensi Kategori Kuantitas Airmata Sebelum Menggunakan Komputer}

\begin{tabular}{lcc}
\hline \multicolumn{1}{c}{ Kategori } & $\mathrm{F}$ & Persentase $(\%)$ \\
\hline Non Dry Eye & 27 & 90.0 \\
\hline Dry Eye Ringan & 1 & 3.3 \\
\hline Dry Eye Sedang & 2 & 6.7 \\
\hline Total & 30 & 100 \\
\hline
\end{tabular}


Dari tabel diatas tabel 3 menunjukkan bahwa dari jumlah 30 orang sampel dengan responden mahasiswa teknik informatika yang menggunakan komputer persentasenya 90\% kuantitas air mata responden termasuk dalam kategori Non Dry Eye.

Dari tabel diatas tabel 4.3 menunjukkan bahwa dari jumlah 30 orang sampel dengan responden mahasiswa teknik informatika yang menggunakan komputer persentasenya 90\% kuantitas air mata responden termasuk dalam kategori Non Dry Eye.

Tabel 4 Distribusi Frekuensi Kategori Kuantitas Airmata Sesudah 2 Jam Menggunakan Komputer

\begin{tabular}{lcc}
\hline \multicolumn{1}{c}{ Kategori } & F & Persentase (\%) \\
\hline Non Dry Eye & 23 & 76.7 \\
\hline Dry Eye Ringan & 3 & 10.0 \\
\hline Dry Eye Sedang & 4 & 13.3 \\
\hline Total & 30 & 100 \\
\hline
\end{tabular}

Pada penelitian ini jumlah total dari hasil tabel 4.4 didapati sebanyak 23 orang (76.7\%) sesudah 2 jam menggunakan komputer dikategorikan mengalami Non Dry Eye, kemudian sebanyak 3 orang $(10.0 \%)$ dikategorikan mengalami Dry Eye Ringan dan 7 orang (13.3\%) dikategorikan Dry Eye Sedang dari jumlah sampel sebanyak 30 orang.

\section{b. Pembahasan}

Berdasarkan tabel 3 hasil pemeriksaan kuantitas airmata sebelum menggunakan komputer didapatkan hasil sebanyak 23 orang (76.7\%) sesudah 2 jam menggunakan komputer dikategorikan mengalami Non Dry Eye, kemudian sebanyak 3 orang (10.0\%) dikategorikan mengalami Dry Eye Ringan dan 7 orang (13.3\%) dikategorikan Dry Eye Sedang dari jumlah sampel sebanyak 30 orang. Hal ini menunjukkan bahwa terjadi penurunan kuantitas airmata setelah menggunakan komputer selama 2 jam.

Seseorang yang menggunakan komputer dalam waktu yang cukup lama juga dihadapkan pada penurunan frekuensi mengedip. Lapisan air mata yang normal dibersihkan dan diganti melalui proses mengedip oleh kelopak mata. Reflek mengedip adalah salah satu reflek tercepat yang sudah ada ketika lahir. Jumlah kedipan bervariasi dengan aktifitas yang berbeda, cepat ketika sedang aktif dan lambat ketika kita sedang sedatif atau berkonsentrasi. Penelitian menunjukkan bahwa frekuensi mengedip pada pengguna komputer menurun drastis selama melakukan aktifitas dengan menggunakan komputer. Hal ini disebabkan oleh konsentrasi terhadap aktifitas dan pergerakan mata yang terbatas sehingga terjadi penurunan produksi air mata atau peningkatan penguapan air mata (Affandi dalam Imgardis teti, 2012).

Penggunaan komputer dalam jarak dekat dan lama membutuhkan kemampuan akomodasi dan konvergensi bola mata yang lebih banyak apabila hal ini berlangsung terus-menerus akan menimbulkan penurunan kemampuan akomodasi dan konvergensi sehingga timbul keluhan kelelahan pada mata, rasa kering, dan 
buramnya penglihatan (Muhammad Irfan Dwiputra Rianil, DKK 2018). Pada penelitian yang dilakukan Muhammad Irfan Dwiputra, DKK 2018 mengatakan bahwa pengguna komputer selama 2 jam, responden berjumlah 32 orang dengan 1 orang termasuk kriteria eklusi, kuantitas air mata mengalami perubahan penurunan secara bermakna $\mathrm{p}=0.015$. Pengguna komputer dalam jangka 2 jam meningkatkan frekuensi refleks berkedip secara bermakna dan menurunkan kuantitas air mata secara bermakna. Sedangkan pada penelitian yang dilakukan Andriana Kirana Puspa, DKK 2018 menyatakan bahwa pengguna komputer dalam waktu lama $88 \%$ mengalami mata kering.

Pada beberapa penelitian yang dilakukan Jurisna Maria Pangemanan, DKK 2014 pada keluhan penglihatan mata terasa berair hasil uji Chi-Square dengan taraf signifikan $(\mathrm{n}=0.005)$ $<(\mathrm{n}=0.003)$. Ini berarti ada hubungan yang signifikan dengan lamanya pengguna computer dengan keluhan penglihatan yaitu pada keluhan mata terasa berair. Sedangkan, pada penelitian yang dilakukan oleh peneliti lain didapatkan hasil uji analisis pada penelitian ini terdapat hubungan lama istirahat dan durasi penggunaan komputer dengan masing-masing $\mathrm{p}$ value $(\mathrm{p}=0,011)$ dan $(\mathrm{p}=0,015)$. Hasil pada penelitian ini menunjukkan bahwa pentingnya istirahat dan pengaturan durasi penggunaan komputer untuk mempertahankan kondisi kuantitas airmata pengguna komputer yang ditunjukan dengan gejala mata berair sebanyak $(66,0 \%)$ (Fauzia Tria Andara Sari, 2018).

\section{KESIMPULAN}

a. Jumlah dari 30 sampel yang dijadikan responden Uji Schirmer Test pada Mahasiswa Teknik Informatika, angkatan 2016 didapatkan hasil bahwa sesudah 2 jam menggunakan komputer kadar air mata mengalami penurunan kadar air mata.

b. Penggunaan komputer dalam jarak dekat dan berlangsung terus-menerus akan menimbulkan penurunan kemampuan akomodasi dan konvergensi sehingga timbul keluhan pada mata seperti mata kering.

\section{PUSTAKA}

Buku :

Hidayat, A. A. (2010). Metode Penelitian Kebidanan dan Analisis Data. Jakarta: Salemba Medika.

Notoatmodjo, S. (2012). Metodologi Penelitian Kesehatan. Jakarta: Rineka Cipta. Pempera, P., Feltzke, M., \& Miskowiak, B. (2014). Are traditional methods of balancing accomodation still useful in the modern optometry office? A comparison of method. Optica Applicata,(1), pp. 7991.

Sangadji, M. D., \& Dr. Sopiah MM., S. (2010). Metodologi Penelitian - Pendekatan Praktis dalam Penelitian. Penerbit ANDI.

Siregar, Sofyan. 2013. Metode Penelitian Kuantitatif. Jakarta: PT Fajar Interpratama Mandiri.

Sudjana. Metode Statistika. Bandung: Tarsito,2002, h. 239-240. 
Sugiono, P. D. (2008). Metode Penelitian Kuantitatif, Kualitatif dan $R \& D$. CV. ALFABETA

Jurnal Online :

A'la RH. Studi Penggunaan Artificial Tears Pada Pasien Dry Eye Syndrome. [serial online] 2016 [dikutip 22 Jan 2019] Tersedia dari URL: http://repository.unair.ac.id/53809/13/FF $\% 20 \mathrm{FK} \% 2041 \% 2016$-ilovepdfcompressed.pdf

Achmad affandi, 2012 dalam Imgardis Teti. GEJALA ASTHENOPIA PADA KASUS COMPUTER VISION SYNDROME DI UNIVERSITAS KOMPUTER INDONESIA BULAN MEI TAHUN 2012. Bandung ; 2012

Andriana Kirana Puspa, Rozalina Loebis, Djohar Nuswantoro. Pengaruh Penggunaan Gadget terhadap Penurunan Kualitas Penglihatan Siswa Sekolah Dasar. [serial online]. [dikutip $30 \mathrm{Mei}$ 2019]. Tersedia dari :

https://ejournal.unisba.ac.id/index.php/gm hc/article/download/2471/pdf

Arief Susanto. Pengenalan Komputer. [serial online] 2009 [dikutip 11 februari 2019]. Tersedia dari : http://ilmukomputer.org/wpcontent/uploads/2010/03/arief_pengenalan komputer.pdf

Elvira. Wijaya NV. Penyakit Mata Kering. [serial onine] 2018 [dikutip 02 Des 2018] Tersedia dari URL: http://www.kalbemed.com/Portals/6/10 2 62CME-

Penyakit\%20Mata\%20Kering.pdf

Fauzia Tria Andara Sari. HUBUNGAN LAMA ISTIRAHAT DAN DURASI PENGGUNAAN KOMPUTER TERHADAP COMPUTER VISION SYNDROME PADA PEMAIN GAME ONLINE. [serial online]. [dikutip $30 \mathrm{Mei}$ 2019]. Tersedia dari :
http://digilib.unila.ac.id/31171/3/3.\%20SKRIP SI\%20TANPA\%20PEM BAHASAN.pdf

GEORGE, O. G. AND OMOKHUA, P. O. COMPARATIVE ANALYSIS OF THE EFFECTS OF TOPICAL ANAESTHETIC AGENTS ON TEAR QUANTITY AND TEAR QUALITY. [serial online] 2010 [dikutip 26 Februari 2019]. Tersedia dari https://www.ajol.info/index.php/jnoa/artic le/view/56632/0

Irsad Sadri. UJI SCHIRMER I SEBELUM DAN SESUDAH 2 JAM MENGGUNAKAN KOMPUTER. [serial online] 2003 [dikutip 13Januari 2019].

Tersedia dari:

http://library.usu.ac.id/download/fk/pnym ata-irsad.pdf

Jhon Gibson. Fisiologi\& Anatomi Modern untuk Perawat. Halaman 305-306.

$2^{\text {nd }}$ Ed. [serial online]. Tersedia dari : https://books.google.co.id/books?id=fhq0 XZVHwAC\&printsec $=$ frontcover $\&$ hl $=\mathrm{id} \&$ source $=$ gbs_ge_summary_r\&cad $=0 \#$ $\mathrm{v}=$ onepage $\& \mathrm{q}=$ air $\% 20 \mathrm{mata} \& \mathrm{f}=$ false

Jurisna Maria Pangemanan, J.S.M.Saerang, Laya. M. Rares. HUBUNGAN LAMANYA WAKTU PENGGUNAAN TABLET COMPUTER DENGAN KELUHAN PENGLIHATAN PADA ANAK SEKOLAH DI SMP Kr. EBEN HEAZER 2 MANADO. [serial online]. [dikutip $30 \mathrm{Mei}$ 2019]. Tersedia dari : https://ejournal.unsrat.ac.id/index.php/ecli $\underline{\text { nic/article/download/5426/4933 }}$

Melati Aisyah Permana, Herry Koesyanto, Mardiana. FAKTOR YANG

BERHUBUNGAN DENGAN KELUHAN COMPUTERVISION SYNDROME (CVS) PADA PEKERJA RENTAL KOMPUTER DI WILAYAH UNNES. [serial online] 2015 [dikutip 5 februari 2019]. Tersedia dari : https://webcache.googleusercontent.com/s 
earch?q=cache:MqPu9fA4gvkJ:https://jou rnal.unnes.ac.id/sju/index.php/ujph/article /view/6372/4761+\&cd=3\&hl=en\&ct=clnk $\underline{\& \mathrm{gl}=\mathrm{id}}$

Muchamad Sugarindra, Zuhdi Allamsyah. IDENTIFIKASI INTERAKSI MANUSIA DAN KOMPUTER BERBASIS COMPUTER VISION SYNDROME PADA UNIT REFINERY CENTRAL CONTROL ROOM. [serial online] Maret 2017 [dikutip 16 februari 2019]. Tersedia dari:

https://webcache.googleusercontent.com/s earch?q=cache:TmVT_wk5V

IJ:https://journal.uii.ac.id/jurnalteknoin/article/download/8338/7109+\&cd $=1 \& \mathrm{hl}=\mathrm{en} \& \mathrm{ct}=\mathrm{clnk} \& \mathrm{gl}=\mathrm{id}$

Muhammad Irfan Dwiputra Riani, Arief Wildan, Andrew Johan. PENGARUH LAMA PENGGUNAAN KOMPUTER TERHADAPKUANTITAS AIR MATA DAN REFLEKS BERKEDIP. [serial online]. [dikutip 30 Mei 2019]. Tersedia dari :

https://ejournal3.undip.ac.id/index.php/medico/ article/download/20667/19397

Muhammad Irfan Dwiputra Rianil, Arief Wildan, Andrew Johan. PENGARUH LAMA PENGGUNAAN KOMPUTER TERHADAP KUANTITAS AIR MATA DAN REFLEKS BERKEDIP. [serial online] 2018 Mei [dikutip 3 Februari 2019]. Tersedia dari :

https://ejournal3.undip.ac.id/index.php/me dico/article/view/20667/19397

Selisca Luthfiana Fadhillah. Faktor-faktor yang Berhubungan dengan Kelelahan Mata pada Pengguna Komputer di Accounting Group PT Bank X, Jakarta. [serial online] 2013 [dikutip 27 februari 2019]. Tersedia dari : http://repository.uinjkt.ac.id/dspace/bitstre am/123456789/26520/1/SELI SCA\%20LUTHFIANA\%20FADHILLAH -FKIK.pdf
Suci Febrianti, Teuku Samsul Bahri. GEJALA COMPUTER VISION

SYNDROME PADA MAHASISWA

KEPERAWATAN. [serial online] 2018

[dikutip 25februari 2019].

Tersedia dari :

http://www.jim.unsyiah.ac.id/FKep/article /viewFile/8430/3715

Suryani. Perbandingan Dry Eye Setelah Operasi Fakoemulsifikasi Antara Letak Insisi Temporal Dengan Letak Insisi Superior [serial online] 2018 [dikutip 23 Februari 2019] Tersedia dari URL: http://digilib.unhas.ac.id/uploaded_files/te mporary/DigitalCollection/Zj c0NTFINTQ3YjJjMjhmZWIyM2YxNzQ xNWM0NDJmNTlkYmY5M $\underline{\mathrm{mYzOQ}==. p d f}$

Syehabudin RN. Insidensi Dry Eyes Pada Pengguna Lensa Kontak Menggunakan Tes Schirmer Dan Ocular Surface Disease Terhadap Mahasiswa Pre Klinik PSKPS Fakultas Kedokteran dan Ilmu Kesehatan UIN Syarief Hidayatulah. [serial online] 2017 [dikutip 13 Des 2018] Tersedia dari URL:

http://repository.uinjkt.ac.id/dspace/handl e/123456789/37480.

Taufan Elfananda, Wahyudi Widada, Ns. Sasmiyanto. PENGARUH TERAPI MADU TERHADAP TINGKATAN NYERI MATA LELAH PADA PEKERJA DI BENGKEL LAS LISTRIK KECAMATAN PATRANG JEMBER. [serial online]. [dikutip 6 februari 2019]. Tersedia dari :

http://digilib.unmuhjember.ac.id/files/disk 1/70/umj-1x-taufanelfa-3496-1-artikel$\underline{1 . p d f}$

Wisnu Eko Saputro. HUBUNGAN

INTENSITAS PENCAHAYAAN, JARAK PANDANG MATA KE LAYAR DAN DURASI PENGGUNAAN KOMPUTER DENGAN KELUHAN COMPUTER VISION SYNDROME. [serial online]. [dikutip 30 Mei 2019]. Tersedia dari : 
JURNAL SEHAT MASADA $\quad$ VOLUME XV NOMOR $1 \quad$ Januari $2021 \quad$ ISSN : 1979-2344

https://media.neliti.com/media/publication s/18798-ID-hubungan-intensitaspencahayaan-jarak-pandang-mata-kelayar-dan-durasi-penggunaa.pdf

Yeni Anggraeni. FAKTOR-FAKTOR YANG BERHUBUNGAN DENGAN

TERJADINYA KELUHAN COMPUTER

VISION SYNDROME (CVS) PADA OPERATOR KOMPUTER PT. BANK KALBAR KANTOR PUSAT TAHUN 2012. [serial online] 2012 [dikutip 1 februari 2019]. Tersedia dari : https://media.neliti.com/media/publication s/193836-ID-faktor-faktor-yang-

berhubungan-dengan-te.pdf 